\title{
Predictors of Response to Endobronchial Coil Therapy in Patients with Advanced Emphysema
}

Dirk-Jan Slebos, MD, PhD ${ }^{1,2}$, Joseph Cicenia, $\mathrm{MD}^{3}$, Frank C. Sciurba, $\mathrm{MD}^{4}$, Gerard J. Criner, $\mathrm{MD}^{5}$, Jorine E. Hartman, $\mathrm{PhD}^{1,2}$, Justin Garner, MBBS BSc MRCP${ }^{6}$, Gaëtan Deslée, $\mathrm{MD}^{7}$, Antoine Delage, $\mathrm{MD}^{8}$, Michael Jantz, $\mathrm{MD}^{9}$, Charles-Hugo Marquette, $\mathrm{MD}, \mathrm{PhD}^{10}$, Charlie Strange, $\mathrm{MD}^{11}$, Umur Hatipoglu, MD², Atul C. Mehta, MD³, Adam S. LaPrad, PhD ${ }^{12}$, Gerald Schmid-Bindert, $M^{13,14}$, Felix JF Herth, MD, PhD ${ }^{15}$, Pallav L. Shah, $\mathrm{MD}^{6,16}$ on behalf of the RENEW Study Group.

1. University of Groningen, University Medical Center Groningen, Groningen, Department of Pulmonary Diseases, The Netherlands

2. University of Groningen, University Medical Center Groningen, Groningen Research Institute for Asthma and COPD, Groningen, The Netherlands

3. Cleveland Clinic Foundation, Cleveland, $\mathrm{OH}$, USA

4. University of Pittsburgh School of Medicine, Pittsburgh, PA, USA

5. Lewis Katz School of Medicine at Temple University, Philadelphia, PA, USA

6. Royal Brompton Hospital and Chelsea \& Westminster Hospitals, London, UK

7. University Hospital of Reims, INSERM U1250, Reims, France

8. Quebec Heart and Lung Institute, Quebec City, Quebec, Canada

9. University of Florida, Gainesville, FL, USA

10. University Nice Sophia Antipolis, IRCAN, ONCOAGE, Nice, France

11. Medical University of South Carolina, Charleston, SC, USA

12. PneumRx, Inc., a BTG International group company, Santa Clara, CA, USA

13. PneumRx GmbH, a BTG International group company, Germany

14. Medical Faculty Mannheim, Heidelberg University, Germany

15. Thoraxklinik and Translational Lung Research Center (TLRC), University of Heidelberg, Heidelberg, Germany

16. National Heart \& Lung Institute, Imperial College, London, UK 


\section{Corresponding Author:}

Dr. Dirk-Jan Slebos, MD PhD

Department of Pulmonary Diseases, AA11

University Medical Center Groningen

PO Box 30001, 9700 RB Groningen, The Netherlands

e-mail: d.j.slebos@umcg.nl

Running head: Responders to Endobronchial Coil Therapy

This article has an online supplement

\section{Author contributions:}

DJS, PLS, FS, GC, AM, ASL, GSB and FJH together designed and executed this analysis. All authors contributed to patient recruitment, follow-up, and revisions of this manuscript. DS, JH, JC, ASL, GSB and PLS drafted the concept and led the writing of the paper, they all had personally reviewed the efficacy data, understand the statistical methods employed for the analysis, and confirmed understanding of this analysis, that the methods are clearly described and that they are a fair way to report the results.

\section{Sources of Support:}

The original RENEW study was supported by PneumRx, Inc., CA, USA. The current post-hoc analysis involved no financial support. 
Conflicts of Interest: DJS is a physician advisor and investigator for PneumRx/BTG. He has received grants, consultancy fees and was reimbursed for trial related expenses. FCS received institutional support from BTG and Pulmonx. GJC has received grants from US NIH and the Department of Defense, consulting from AstraZeneca, Boehringer Ingelheim, Holaira, Mereo, Third Pole, PneumRX, Pulmonx, Pearl, Amirall, CSA Medical, Broncus, AVISA, Lungpacer and GlaxoSmithKline; and contracted clinical trials from AstraZeneca, Avisa, Mereo,Boehringer Ingelheim, Broncus, GlaxoSmithKline, Lungpacer,Novartis, Pulmonx, PneumRx/BTG, and Yungjin. AD consultancy for Boehringer Ingelheim. CS has received grants to MUSC from HE, PneumRx and Pulmonx for fronchoscopic therapies for COPD. He has consulted for CSA Medical, PneumRx, Pulmonx and Uptake Medical. ASL is an employee of PneumRx, Inc. GSB works as Medical Director for PneumRx and lectures at the Medical Faculty Mannheim of Heidelberg University. PLS reports personal fees from Boston Scientific, Broncus, CSA Medical, Creo Medical, Nuvairia Olympus, Medtronic and PneumRx/BTG as consultant on scientific advisory board, other sponsorship to Imperial College for a bronchoscopy course by ERBE, Cook Medical, Medtronic, Boston Scientific, Broncus, Pulmonx, Olympus, \& PneumRX/BTG, outside the submitted work. He has been an investigator on clinical trials with endobronchial valves, endobronchial coils, thermal ablation and the airway bypass procedure. 
Abbreviation list

$\begin{array}{lll}\text { 6MWT } & - & \text { 6-minute walk test } \\ \text { 6MWD } & - & \text { 6-minute walk distance } \\ \text { COPD } & - & \text { chronic obstructive pulmonary disease } \\ \text { FEV } 1 & - & \text { forced expiratory volume in one second } \\ \text { HRCT } & - & \text { high resolution computed tomography } \\ \text { LAA } & - & \text { low attenuation area } \\ \text { MCID } & - & \text { minimal clinical important difference } \\ \text { mMRC } & - & \text { modified medical research counsil dyspnea score } \\ \text { RV } & - & \text { residual volume } \\ \text { SGRQ } & - & \text { Saint George's Respiratory Questionnaire } \\ \text { QCT } & - & \text { quantitative computed tomography } \\ \text { QVM } & - & \text { quantitative visual match }\end{array}$

This article has an online data supplement, which is accessible from this issue's table of contents online at www.thorax.bmj.com 


\section{ABSTRACT}

\section{Background}

The RENEW trial demonstrated improvements in quality of life, pulmonary function, and exercise performance after endobronchial coil treatment. The aim of this study was to identify parameters associated with superior clinical outcomes.

\section{Methods}

Quantitative computerized analysis by an independent radiology laboratory and a qualitative evaluation by five blinded experts of the baseline thoracic computed tomograms (CT) were performed. Univariate and multivariate logistic regression analyses were performed to elucidate characteristics associated with clinical response.

\section{Results}

In total 125 patients received coil treatment and had evaluable 12 month follow up results. Of these, 78 patients received treatment of lobes with the highest emphysematous destruction determined by quantitative $\mathrm{CT}(\mathrm{QCT})$ analysis $(\mathrm{QVM}+)$, and 47 received treatment in at least one lobe that was not the most destroyed (QVM-). From the 78 patients with QVM+ treatment, a subgroup of 50 patients (64\%) was identified with baseline residual volume $>200 \%$ predicted, emphysema score $>\mathbf{2 0 \%}$ low attenuation area (LAA), and absence of airways disease. In this subgroup, greater lobar residual volume reduction in the treated lobes was achieved, which was associated with significant improvement in $\mathrm{FEV}_{1}(+15,2 \%, \mathrm{SE} 3.1)$, SGRQ (-12 points, SE 2), and residual volume (RV) (-0.57L, SE 0.13). 


\section{Discussion}

This post-hoc analysis showed that both significant hyperinflation ( $\mathrm{RV} \geq 200 \%$ predicted) and CT analysis are critical for patient selection and treatment planning for endobronchial coil therapy. QCT is important to identify optimal lobar treatment and to exclude patients with insufficient emphysema ( $<20 \%$ LAA), while visual assessment identifies patients with signs of airway disease associated with worse outcomes.

Clinical trial registration $\mathrm{nr}$.:

NCT01608490

\section{Key words:}

bronchoscopy, emphysema, endobronchial coils, lung volume reduction, HRCT, COPD 


\section{INTRODUCTION}

COPD patients with advanced emphysema and severe lung hyperinflation have limited effective treatment options. Generally, lung volume reduction surgery or lung transplantation can be offered to those who meet strict criteria. However, these procedures are infrequently performed due to significant morbidity and mortality.[1] Alternatively, use of endobronchial valves is limited to individuals with intact lobar fissures. Bronchoscopic lung volume reduction using shape-memory nitinol endobronchial coils is a minimally invasive treatment option. $[2,3]$ The safety and effectiveness of endobronchial coils has been evaluated in several studies showing significant benefit of coil treatment on pulmonary function outcomes, exercise performance and quality of life.[4-11]

RENEW (NCT01608490), an international, multicenter randomized controlled trial, assessed endobronchial coil treatment in patients with severe lung hyperinflation and homogeneous or heterogeneous emphysema.[4] The primary outcome measure demonstrated a small but statistically significant improvement in the 6-minute walk distance (6MWD). Larger and statistically significant improvements were observed in outcome measures of Residual Volume (RV), Forced Expiratory Volume in 1 second $\left(\mathrm{FEV}_{1}\right)$ and Saint Georges Respiratory Questionnaire (SGRQ) versus control group patients (regular care) at 12 months. The RENEW primary analysis showed pre-specified subgroups with superior outcomes, namely patients with more hyperinflation ( $R V \geq 225 \%$ pred) and patients with heterogeneous emphysema distribution, but a statistical analysis for predictors of response was not performed.[4] Of note, quantitative measures of the inspiratory and expiratory CT scans were not assessed in the primary analysis. 
In this post-hoc analysis of the RENEW trial, we performed lobar-based quantitative computed tomography (QCT) measurements and a qualitative expert image review. The purpose of this post-hoc analysis was to identify baseline predictors including quantitative CT measures that identify patients most likely to significantly benefit from endobronchial coil therapy. 


\section{METHODS}

\section{Patient population}

The patients' characteristics and primary results of the RENEW trial have previously been reported.[4] Of 158 patients randomized to the RENEW treatment group, 125 completed bilateral treatment and twelve-month follow-up and had evaluable inspiratory and expiratory CT scans at baseline and 12-month follow-up and were included in the post-hoc analysis (Figure 1). Baseline characteristics are shown in Table 1. The RENEW trial was approved by all the 31 trial sites medical ethical review committees, and all patients provided written informed consent.

\section{Quantitative CT analysis (QCT)}

After the RENEW 12-month primary endpoint follow-up visit and study un-blinding, HRCT scans for the coil-treated group were analyzed quantitatively (QCT) (Thirona, Nijmegen, The Netherlands). The QCT analysis included volumetric and densitometry assessment at a lung and lobar basis. Percentage emphysema was calculated as \% of low attenuation areas below 950HU on inspiratory scans (\%LAA950). Percentage air trapping was calculated as \%LAA below 856HU on expiratory scans (\%LAA856). Percentage heterogeneity (difference in \%LAA950 between ipsilateral lobes) and \%fissure integrity (for major fissures on inspiratory scans) were also measured. A "heterogeneous" patient was defined as having $\geq 15 \%$ ipsilateral difference in \%LAA950 in both lungs, a "homogenous" patient as having $<15 \%$ ipsilateral difference in \%LAA950 in both lungs. A "mixed" patient had one heterogeneous lung and one homogeneous lung. 
Lobar volume change was calculated as the total change in lobar volume of both treated lobes comparing baseline to 12 months post coil treatment, assessed both with expiratory scans (lobar RV change) and inspiratory scans (lobar TLC change).

Agreement between quantitative and visual analyses of the HRCT (QVM + and QVM-)

The most damaged lobe of each lung determined by QCT analysis was compared to the lobe target determined by the RENEW visual analysis. The RENEW trial used a visual CT analysis to select the most damaged lobes for coil treatment based on a 0 to 5 scoring system of lobar destruction (see Supplement S1). If the quantitative and visual analyses agreed on both treated lobes, the patient was determined to be "quantitative-visual match-positive" or QVM+. If disagreement was observed in one or both treated lobes, the patient was designated as "quantitative-visual match-negative, or QVM-".

\section{Visual CT Assessment}

Five experts (one radiologist, four pulmonologists) conducted a post hoc blinded visual assessment of all baseline inspiratory CTs. Experts noted visual findings including bronchial wall thickening, bronchiectasis, fibrosis/scarring, and suspected pulmonary hypertension. Methods are described in the online data Supplement S1.

\section{Statistical analysis}

Univariate analysis and Pearson correlation coefficients were used to investigate associations between QCT measured outcomes, potential baseline predictors and clinical response outcomes. A multivariate logistic regression model was used to identify the association 
between baseline measures including QCT and lobar volume reduction at 12 months. Multivariate logistic regressions were performed with stepwise control using minimum Akaike Information Criterion (AICC) stopping rule in forward direction. Clinical response was measured by the RENEW study endpoints at 12 months (6MWD, FEV $1, R V, S G R Q$ and the minimum clinically important difference (MCID) level response to these four RENEW endpoints (MCID: 6MWD of $25 \mathrm{~m}[12]), \mathrm{FEV}_{1}$ of $10 \%[13], \mathrm{RV}$ of $-0.35 \mathrm{~L}[14]$, SGRQ total score of -4 points[15]).

The QCT measures used in this analysis were \%emphysema, \%air trapping, \%heterogeneity, QVM+, and \%fissure integrity. Patient baseline characteristics included demographics (age, BMI), PFTs (plethysmographic lung volumes and forced spirometry), visual CT findings, and treatment factors (total number of coils per lobe volume, and \% proportion of each coil size). Differences in baseline characteristics between QVM+ and QVM- patients were evaluated using two-sample t-test or Fisher's exact test. All statistical analyses were performed using SAS ${ }^{\circledR}$ version 9.4 (SAS Institute Inc., Cary NC, USA). P-values $<0.05$ were considered statistically significant. 


\section{RESULTS}

Association between change in QCT measures and clinical response measures

We examined the association between change in QCT measures and clinical response MCIDs from baseline to 12 months follow up (S2 Table, Supplement). Change in lobar RV in the treated lobes was the only QCT measure that was significantly associated $(p<0.05)$ with all four clinical outcomes. This establishes reduction in expiratory lobar RV as a mechanistically plausible primary effect of the coils that can be analysed in establishing baseline predictors of response.

Impact of matching of QCT and visual CT targeting of lobe with greatest emphysema (QVM) Using targeting based on the visual scoring algorithm, $38 \%$ of patients $(47 / 125)$ received one or both treatments in the ipsilateral lobe of lesser quantitative CT emphysematous destruction and were designated QVM-. The majority of the QVM- treatments occurred in lungs defined as homogeneous by QCT (Figure 2). The QVM+ subgroup, in which the visual algorithm matched the QCT lobe of greatest destruction, had greater heterogeneity at baseline $(p<0.0005)$, greater $\%$ emphysema $(p<0.005)$ and more air trapping $(p<0.005)$ compared to the QVM- group (Table $1)$.

The multivariate analysis with adjustment for the identified baseline imbalances between the two subgroups showed that QVM+ patients achieved significantly more expiratory lobar volume reduction at 12 months compared to QVM- patients (mean of $-0.37 \pm 0.05$ litres (L) versus $-0.13 \pm 0.08 \mathrm{~L} ; \mathrm{p}=0.0064)$, even after accounting for baseline differences in \%heterogeneity, \%air trapping, and \%emphysema (S3 Table, Supplement). In addition, between-group differences in change in 6MWD $\left(+15.4 \mathrm{~m}, 95 \% \mathrm{Cl}[-12.1,42.9], \mathrm{FEV}_{1}(+6.7 \%, 95 \%\right.$ 
$\mathrm{Cl}[-0.8,14.2]), \mathrm{RV}(-0.12 \mathrm{~L}, 95 \% \mathrm{Cl}[-0.41,0.17]$, and SGRQ $(-0.6$ point in total score, $95 \% \mathrm{Cl}[-$ 5.5,4.3] all favored QVM+ patients. Furthermore, QVM+ emerged as the only significant QCTbased predictor of lobar RV change ( $p=0.02)$ ( $S 4 a+b$ Tables, Supplement).

Thus, lobar selection with QCT emerged in this analysis as a previously unknown covariate in RENEW that may have obscured the response profile of endobronchial coil therapy in this trial. To account for this, we excluded QVM- patients from the subsequent analyses in which we examine baseline predictors of response.

\section{Baseline predictors of superior response to coil treatment in QVM+ population}

Higher baseline \%emphysema score and absence of airways disease on visual CT review were associated $(p<0.05)$ with lobar RV reduction at 12 months (Figure $3 a+b$ and Table 2). Higher baseline RV\% predicted approached significance $(p=0.071)$ in the multivariate stepwise model. We next applied a lobar RV change threshold of $-320 \mathrm{~mL}$ to determine the lowest baseline value for RV\% predicted and \% emphysema score that resulted in a lobar RV response at 12 months. The threshold of $-320 \mathrm{~mL}$ for lobar RV change was determined using an MCID analysis anchored to RV change measured via body plethysmography (Table S5, supplement). Patients with baseline $\mathrm{RV}<200 \%$ predicted or with \% emphysema score $<20 \%$ in either targeted lobe did not achieve clinically meaningful lobar RV reduction (Figure S6, Supplement).

Sixty-four percent of patients in the QVM+ subgroup (50/78) met all three identified volume reduction criteria: $R V \geq 200 \%$ predicted, $\% L A A \geq 20 \%$, and no visually determined presence of airways disease at baseline. This volume reduction criteria subgroup ( $\mathrm{N}=50)$ demonstrated significant clinical improvement at one-year post-treatment (mean) for $\mathrm{RV}-570 \mathrm{ml}, \mathrm{FEV}_{1,97} \mathrm{ml}$, FEV $_{1,15.2} \%$, and SGRQ -12 points $(p<0.01)$ but not for 6MWT (0.1935) (Table 3 ) compared to 
patients who did not meet these criteria. Importantly, this resulted in significant improvements in clinical responder rates when comparing the volume reduction criteria subgroup to those that did not meet these criteria (Figure 4).

\section{Safety in improved patient selection group}

We examined the one-year safety profile in all RENEW treatment patients who completed the 12-month follow-up visit $(\mathrm{N}=125)$ to assess the safety impact of improved patient selection. No differences approached significance between the Volume Reduction Criteria subgroup and the subgroup without all volume reduction criteria (Table 4). 


\section{DISCUSSION}

Following early lung volume reduction trials, post-hoc subgroup analysis proposed responder profiles that still define the current use of both surgical therapies and valve therapies.[16,17] The responder subgroup identified in the randomized, controlled VENT trial has been confirmed prospectively, providing necessary selection criteria for real-world therapeutic adoption of endobronchial valves.[18-22] Similarly, this RENEW post-hoc analysis offers rational predictors of response to coil therapy that can now be prospectively confirmed as well.

Endobronchial coils have shown effectiveness in both heterogeneous and homogenous disease, however, no clear single mechanism of action has been defined. Where valves and other therapies based on atelectasis or injury-response fibrosis benefit from the rich evidence base of response mechanisms in lung volume surgery, the mechanisms driving the effects of coil treatment have yet to be defined[23,24]. Despite its early stage, there is accumulating evidence supporting multiple mechanistic effects on the lung induced by coil placement such as reducing static hyperinflation, improving airway resistance, promoting the airway tethering effect, and reducing dynamic hyperinflation[10,25-27]. RENEW has provided substantial opportunity for post-hoc analysis and improved understanding of coil mechanisms and predictors of response.[4] While the design of coils as local, non-blocking devices creates the potential for multiple mechanisms of action, we propose volume reduction as the primary objective of coil therapy and have confirmed the association of lobar RV reduction with clinical responsiveness at one-year post-treatment. We also identified three baseline criteria with proposed inclusion thresholds ( $R V \geq 200 \%$ predicted, emphysema score $\% L A A \geq 20$, and no presence of airways disease on visual (T) which defined a patient subgroup achieving clinically significant pulmonary function and volume reduction outcomes at 12-months post coil treatment. 
Treating the most damaged lobe was shown to be most strongly associated with lobar volume reduction, and we discovered that over $1 / 3$ of patients treated in RENEW did not receive bilateral treatment in the most destroyed lobes according to QCT. When the most damaged lobes were treated (QVM+ subgroup), substantial improvements in physiological and clinical outcomes were demonstrated when compared to the QVM- subgroup. This suggests that using $\mathrm{QCT}$, rather than visual analysis, to target the most damaged lobes for treatment may be associated with improved outcomes in coil treated patients. QCT-visual mismatching was much more common in homogenous patients compared to heterogenous patients; this has important implications given that most volume reduction studies focus almost exclusively on heterogenous patients where the difference between QCT and visual lobar targeting is small and/or negligible. This analysis suggests important limitations of visual lobe targeting for complex and novel interventional therapies, especially in the context of homogeneous patients. There are limitations to this post-hoc analysis, principally the small number of patients because of the exclusion of QVM- treated patients. This is a retrospective subgroup analysis with potential small-n effects. However, the NETT post-hoc responder subgroup represented $11 \%$ of the total study population (139/1218 patients with upper-lobe predominant, heterogenous emphysema and low baseline exercise tolerance), and the VENT post-hoc responder subgroup represented approximately $20 \%$ of the study population (68/321 patients with intact fissures and heterogeneous emphysema). These post-hoc analyses from 2003[17] and 2010[16] have effectively established appropriate patient selection criteria for these therapies still in use today. We also acknowledge the potential of confounding influences among the factors which emerged as significant in our analysis, particularly for the findings of airway wall thickening which was not under protocol for this analysis. 
This analysis is based on a quantitatively measured endpoint (CT expiratory lobar volume) that is somewhat independent of patient effort, although the expiratory scans were not gated using spirometry (see Supplement). Many of the predictors found in our analysis reached statistical and clinical significance despite small subgroups. Our findings are clinically rational and consistent with published literature from earlier emphysema trials.[11,16-18] Our results are promising given that nearly half (44\%) of the volume reduction criteria subgroup is comprised of patients with bilateral homogeneity of disease $(<15 \%$ ipsilateral difference at $-950 \mathrm{HU})$, a group of patients not generally considered for lung volume reduction surgery.[1] The REACTION trial exploring physical activity change and physiologic response patterns in coil-treated patients is ongoing and may shed light on this intriguing hypothesis (NCT02179125).

While quantitative assessment of the HRCT is much more reliable in precise emphysema scoring and fissure completeness[28,29], subtle airway wall changes, magnitude of bronchial wall thickening and mild bronchiectasis, and (post-) infectious consolidations are much more difficult to quantify. Although expert CT readers do not have a solid consensus[30], it is possible to make a judgement with clinical implications[28,31] and a thorough qualitative inspection with clinical interpretation of the findings of these features, in addition to routine QCT, is key in selecting out patients with relevant airway disease, who are less likely to benefit from coil treatment.

In conclusion, we identified three baseline criteria with proposed inclusion thresholds ( $R V \geq 200 \%$ predicted, emphysema score $\% \mathrm{LAA} \geq 20$, and absence of airways disease on visual CT) that defined a patient subgroup achieving clinically significant pulmonary function and volume reduction outcomes at 12 -months post coil treatment. Patients selected for lobar volume reduction with endobronchial coil treatment should meet all these criteria, and lobe targets 
should be confirmed with densitometry analysis to ensure treatment in the lobes of greater destruction. This post-hoc analysis of RENEW data proposes patient selection criteria that improve response to endobronchial coils. These findings warrant prospective confirmation to establish the profile of patients with severe emphysema who should be offered this treatment. 


\section{ACKNOWLEDGEMENTS}

The authors thank PneumRx for statistical and writing support. There was no financial support to any author.

\section{The members of the RENEW Study Group include:}

Thoraxklinik/University of Heidelberg: F.J.F. Herth, D. Gompelmann, M. Schuhmann, R. Eberhardt, D. Harzheim, B. Rump; University Medical Center, Groningen: D.J. Slebos, N. Ten Hacken, K. Klooster, J.E. Hartman, S. Augustijn; Royal Brompton and Chelsea Westminster Hospitals: P.L Shah, C. Caneja, W. McNulty, J. Garner; CHU de Reims-Hôpital Maison Blanche: G. Deslée, H. Vallerand, S. Dury, D. Gras, M. Verdier; CHU de Nice-Hôpital Pasteur: C.H. Marquette, C. Sanfiorenzo, C. Clary, C. Leheron, J. Pradelli, S. Korzeniewski, P. Wolter,T. Arfi, F. Macone, M. Poudenx, S. Leroy, A. Guillemart, J. Griffonet; Medical University of South Carolina (MUSC): C. Strange, R. Argula, G. Silvestri, J.T. Huggins, N. Pastis, D. Woodford, L. Schwarz, D. Walker; Temple University Hospital: G. Criner, J. Mamary, N. Marchetti, P. Desai, K. Shenoy, J.L. Garfield, J. Travaline, H. Criner, S. Srivastava-Malhotra, V. Tauch; NYPH/CUMC New York: R. Maxfield, K. Brenner, W. Bulman, B.A. Whippo, P.A. Jellen; Northwestern University Feinberg School of Medicine: R. Kalhan, C.T. Gillespie, S. Rosenberg, M. McAvoy DeCamp, A.S. Rogowski, J. Hixon; University of Texas Health Sciences Center at San Antonio: L.F. Angel, O. Dib; University of Pittsburgh Medical Center: F.C. Sciurba, D. Chandra, M. Crespo, J. Bon Field, J. Rahul Tedrow, C. Ledezma, P. Consolaro, M. Beckner; Beth Israel Deaconness Medical Center: A. Majid, G. Cheng, J. Cardenas-Garcia, D. Beach, E. Folch, A. Agnew, W. Hori, A. Nathanson; Duke University Medical Center: M. Wahidi, S. Shofer, M. Hartwig, K. Mahmood, E. Smathers; Illinois Lung and Critical Care Institute (OSF Healthcare Systems): W.Tillis, K.Verma, D.Taneja, M.Peil, S.Chittivelu, P.Doloszycki, P.E. Whitten, B. Aulakh, O. Ikadios, J. Michel, J. Crabb, B. McVay, A. Scott, E.A. Pautler; Pulmonary, Critical Care and Sleep Medicine Consultants (PLLC): T.A. Connolly, J.F. Santacruz, L. Kopas, R. Parham, B. Solid; Pulmonary and Critical Care Associates of Baltimore: W. Krimsky, F. Gregoire, S. King; Cleveland Clinic Foundation: A. Mehta, F. Almeida, T. Gildea, J. Cicenia, M. Machuzak, S. Sethi, Y.M. Meli, J. Baran, R. Rice, D. Faile; Franciscan Research Center: 
N. Rai, K. Jensen, R. Kahlstrom, A. Haroon, R. Ionita, F. White, D. Watkins, B. Moore; Cedars Sinai Medical Center: H. Soukiasian, H. Merry, Z. Mosenifar, S. Ghandehari, D. Balfe, J. Park, R. Mardirosian; University of Wisconsin School of Medicine and Public Health: J.S. Ferguson, J. Kanne, D. Sonetti, D. Modi, M. Regan, J. Maloney, M. Hackbarth, M. Gilles, A. Harris, A.Maser; Yale University School of Medicine, J.T. Puchalski, C. Rochester, J. Possick, K. Johnson, Z. Dabre; University of Illinois Hospital and Health Sciences System: K. Kovitz, M. Joo, J. DeLisa; El Camino Hospital / Palo Alto Medical Foundation / Sutter Health: S.V. Villalan, G. Krishna, J. Canfield, A. Marfatia, E. Selley, S.V. Villalan; Mayo Clinic: J. Utz, D. Midthun, R. Kern, E.S. Edell, L.L. Boras (née Kosok); University of Michigan: S .Gay, K.A. Bauman, M. King Han, R.L. Sagana, K. Nelson, C. Meldrum; University of Florida Gainesville: M. Jantz, H.J. Mehta, C. Eagan, J. West; Hôpital Laval: A. Delage, S. Martel, P. LeBlanc, F.Maltais, Y.Lacasse, N. Lampron, F.Laberge, J.Milot, J. Picard, M.J. Breton; University of Alabama at Birmingham: M.Dransfield, J.M. Wells, S.Bhatt, P.Smith, E.N.Seabron-Harris; National Jewish Health: K. Hammond, C.Egidio. 


\section{REFERENCES}

1 Vogelmeier CF, Criner GJ, Martinez FJ, et al. Global Strategy for the Diagnosis, Management, and Prevention of Chronic Obstructive Lung Disease 2017 Report. GOLD Executive Summary. Am J Respir Crit Care Med. 2017;195 (suppl 5):557-582.

2 Herth FJF, Slebos DJ, Criner GJ, et al. Endoscopic Lung Volume Reduction: An Expert Panel Recommendation - Update 2017. Respiration. 2017;94 (suppl 4):380-388.

3 Shah PL, Herth FJ, van Geffen WH, et al. Lung volume reduction for emphysema. Lancet Respir Med. 2016;.

4 Sciurba FC, Criner GJ, Strange C, et al. Effect of Endobronchial Coils vs Usual Care on Exercise Tolerance in Patients With Severe Emphysema: The RENEW Randomized Clinical Trial. JAMA. 2016;315 (suppl 20):2178-2189.

5 Slebos DJ, Klooster K, Ernst A, et al. Bronchoscopic Lung Volume Reduction Coil treatment of patients with severe heterogeneous emphysema. Chest. 2012;142:574-582.

6 Herth FJ, Eberhard R, Gompelmann D, et al. Bronchoscopic lung volume reduction with a dedicated coil: a clinical pilot study. Ther Adv Respir Dis. 2010;4 (suppl 4):225-231.

7 Deslee G, Klooster K, Hetzel M, et al. Lung volume reduction coil treatment for patients with severe emphysema: a European multicentre trial. Thorax. 2014;69 (suppl 11):980-986. 
8 Shah P, Zoumot Z, Bicknell S, et al. Endobronchial coils for the treatment of severe emphysema with hyperinflation (RESET): a randomised controlled trial. Lancet Respir Med. 2013;1 (suppl 3):233-240.

9 Zoumot Z, Kemp SV, Singh S, et al. Endobronchial Coils for Severe Emphysema Are Effective Up to 12 Months following Treatment: Medium Term and Cross-Over Results from a Randomised Controlled Trial. PLoS One. 2015;10 (suppl 4):e0122656.

10 Klooster K, Ten Hacken NH, Franz I, et al. Lung volume reduction coil treatment in chronic obstructive pulmonary disease patients with homogeneous emphysema: a prospective feasibility trial. Respiration. 2014;88 (suppl 2):116-125.

11 Deslee G, Mal H, Dutau H, et al. Lung Volume Reduction Coil Treatment vs Usual Care in Patients With Severe Emphysema: The REVOLENS Randomized Clinical Trial. JAMA. 2016;315 (suppl 2):175-184.

12 Holland $\mathrm{AE}$, Hill $\mathrm{CJ}$, Rasekaba $\mathrm{T}$, et al. Updating the minimal important difference for sixminute walk distance in patients with chronic obstructive pulmonary disease. Arch Phys Med Rehabil. 2010;91 (suppl 1532-821; 0003-9993; 2):221-225.

13 Donohue JF. Minimal clinically important differences in COPD lung function. COPD. 2005;2 (suppl 1):111-124.

14 Hartman JE, Ten Hacken NH, Klooster K, et al. The minimal important difference for residual volume in patients with severe emphysema. Eur Respir J. 2012;40 (suppl 5):1137-1141. 
15 Jones PW. St. George's Respiratory Questionnaire: MCID. COPD. 2005;2 (suppl 1):75-79.

16 Sciurba FC, Ernst A, Herth FJ, et al. A randomized study of endobronchial valves for advanced emphysema. N Engl J Med. 2010;363 (suppl 13):1233-1244.

17 Fishman A, Martinez F, Naunheim $\mathrm{K}$, et al. A randomized trial comparing lung-volumereduction surgery with medical therapy for severe emphysema. $N$ Engl J Med. 2003;348 (suppl 21):2059-2073.

18 Klooster $\mathrm{K}$, ten Hacken NH, Hartman JE, et al. Endobronchial Valves for Emphysema without Interlobar Collateral Ventilation. N Engl J Med. 2015;373 (suppl 24):2325-2335.

19 Davey C, Zoumot Z, Jordan S, et al. Bronchoscopic lung volume reduction with endobronchial valves for patients with heterogeneous emphysema and intact interlobar fissures (the BeLieVeR-HIFi study): a randomised controlled trial. Lancet. 2015;386 (suppl 9998):1066-1073.

20 Kemp SV, Slebos DJ, Kirk A, et al. A Multicenter RCT of Zephyr(R) Endobronchial Valve Treatment in Heterogeneous Emphysema (TRANSFORM). Am J Respir Crit Care Med. 2017;

21 Valipour A, Slebos DJ, Herth F, et al. Endobronchial Valve Therapy in Patients with Homogeneous Emphysema. Results from the IMPACT Study. Am J Respir Crit Care Med. 2016;194 (suppl 9):1073-1082.

22 Criner GJ, Sue R, Wright S, et al. A Multicenter RCT of Zephyr(R) Endobronchial Valve Treatment in Heterogeneous Emphysema (LIBERATE). Am J Respir Crit Care Med. 2018; 
23 Kramer MR, Refaely Y, Maimon N, et al. Bilateral endoscopic sealant lung volume reduction therapy for advanced emphysema. Chest. 2012;142 (suppl 5):1111-1117.

24 Herth FJ, Valipour A, Shah PL, et al. Segmental volume reduction using thermal vapour ablation in patients with severe emphysema: 6-month results of the multicentre, parallelgroup, open-label, randomised controlled STEP-UP trial. Lancet Respir Med. 2016;4 (suppl 3):185-193.

25 Makris D, Leroy S, Pradelli J, et al. Changes in dynamic lung mechanics after lung volume reduction coil treatment of severe emphysema. Thorax. 2018;73 (suppl 6):584-586.

26 Slebos DJ, Hartman JE, Klooster K, et al. Bronchoscopic Coil Treatment for Patients with Severe Emphysema: A Meta-Analysis. Respiration. 2015;90 (suppl 2):136-145.

27 Kloth C, Thaiss WM, Hetzel J, et al. Impact of endobronchial coiling on segmental bronchial lumen in treated and untreated lung lobes: Correlation with changes in lung volume, clinical and pulmonary function tests. Eur Radiol. 2016;26 (suppl 7):2176-2183.

28 COPDGene CT Workshop Group, Barr RG, Berkowitz EA, et al. A combined pulmonaryradiology workshop for visual evaluation of COPD: study design, chest CT findings and concordance with quantitative evaluation. COPD. 2012;9 (suppl 2):151-159.

29 Koenigkam-Santos M, Puderbach M, Gompelmann D, et al. Incomplete fissures in severe emphysematous patients evaluated with MDCT: incidence and interobserver agreement among radiologists and pneumologists. Eur J Radiol. 2012;81 (suppl 12):4161-4166. 
30 Gupta S, Siddiqui S, Haldar P, et al. Qualitative analysis of high-resolution CT scans in severe asthma. Chest. 2009;136 (suppl 6):1521-1528.

31 Nambu A, Zach J, Schroeder J, et al. Quantitative computed tomography measurements to evaluate airway disease in chronic obstructive pulmonary disease: Relationship to physiological measurements, clinical index and visual assessment of airway disease. Eur J Radiol. 2016;85 (suppl 11):2144-2151. 


\section{FIGURE Legends}

Figure 1. Flow Diagram of Subjects Included in This Analysis

Figure 2. Baseline QCT characteristics stratified by QCT subgroup.

Figure legend: Baseline QCT characteristics stratified by QCT subgroup. (A) Proportion of treated heterogeneous ( $\geq 15 \%$ ipsilateral difference in \%LAA -950 HU) and homogeneous lobes (<15\% ipsilateral difference), stratified by whether the treated lobes were QVM+ or QVM-. (B) Proportion of treated patients with heterogeneous (both lungs), homogeneous (both lungs), or mixed (one heterogeneous lung and one homogeneous lung) disease, stratified by whether both lobes were QVM+ or whether one/both lobes were QVM+.

Figure 3a. Scatterplot of emphysema score versus lobar RV reduction in responder analysis cohort $(\mathrm{N}=78)$.

Figure legend: The relationship between lobar RV volume change and baseline \% emphysema score in treated patients. In this figure, \% emphysema is represented as the smaller lobar \%LAA $-950 H U$ score of the two treated lobes.

Figure 3b. Expiratory Lobar Volume Reduction in Treated Lobes by Visual Presence of Airway Disease in Responder Analysis Cohort ( $\mathrm{N}=78)$

Figure legend: Subjects receiving a score of " 2 " or " 3 " ( $n=19)$ for presence of airways disease ("Airway Disease") on visual CT achieved significantly ( $p=0.0117)$ less expiratory lobar volume at 12-months post coil treatment than patients with scores of " 0 " or " 1 " ( $N=59$ ) ("No Airway Disease").

Figure 4. Responder rates in patients with and without identified predictive criteria for response

Figure legend: Volume reduction criteria were "No airway disease", $L A A \geq 20 \%, R V \geq 200 \%$ predicted. Patients who met those criteria, had significantly higher response rates in clinical endpoints, using standard MCID levels: RV -350ml, FEV1 10\%, 6MWD 25m, SGRQ -4 points. 


\section{TABLES}

Table 1. Baseline Characteristics of All RENEW Coil-Treated Patients and Patients Stratified by QCT Subgroup.

\begin{tabular}{|c|c|c|c|c|}
\hline Characteristic* & $\begin{array}{l}\text { RENEW } \\
(\mathrm{N}=125)^{\dagger}\end{array}$ & $\begin{array}{l}\text { QVM+ } \\
(\mathrm{N}=78)\end{array}$ & $\begin{array}{l}\text { QVM- } \\
(\mathrm{N}=47)\end{array}$ & P-value ${ }^{\ddagger}$ \\
\hline Age & $63.2 \pm 8.1$ & $62.9 \pm 8.1$ & $63.7 \pm 8.3$ & 0.6102 \\
\hline Gender, \% Male & $46.4(58)$ & $47.4(37)$ & $44.7(21)$ & 0.8536 \\
\hline BMI & $24.9 \pm 4.6$ & $24.9 \pm 4.6$ & $24.9 \pm 4.6$ & 0.9649 \\
\hline BODE & $6.0 \pm 1.3$ & $6.1 \pm 1.3$ & $5.8 \pm 1.2$ & 0.3184 \\
\hline Mean Comorbidities & $2.6 \pm 2.1$ & $2.7 \pm 2.1$ & $2.3 \pm 1.9$ & 0.2910 \\
\hline$\% 4$ or More Comorbidities & $29.6(37)$ & $32.1(25)$ & $25.5(12)$ & 0.5449 \\
\hline \% Cardiac Comorbidities & $24.8(31)$ & $30.8(24)$ & $14.9(7)$ & 0.0555 \\
\hline 6MWD, Meters & $314.1 \pm 79.9$ & $313.8 \pm 76.9$ & $314.6 \pm 85.6$ & 0.9582 \\
\hline RV \% Predicted & $244.9 \pm 38.5$ & $246.8 \pm 40.6$ & $241.8 \pm 34.8$ & 0.4883 \\
\hline$\% R V \geq 225 \%$ & $71.2(89)$ & $74.4(58)$ & $66.0(31)$ & 0.4149 \\
\hline $\mathrm{RV} / \mathrm{TLC}$ & $66.8 \pm 6.7$ & $67.1 \pm 7.3$ & $66.4 \pm 5.7$ & 0.5851 \\
\hline $\mathrm{FEV}_{1} \%$ Predicted, PB & $25.6 \pm 6.1$ & $25.8 \pm 6.4$ & $25.5 \pm 5.8$ & 0.7813 \\
\hline SGRQ Total Score & $60.0 \pm 12.7$ & $60.2 \pm 13.6$ & $59.7 \pm 11.1$ & 0.8344 \\
\hline$\%$ Heterogeneous ${ }^{\S}$ & $19.2(24)$ & $28.2(22)$ & $4.3(2)$ & 0.0001 \\
\hline \% Homogeneous & $56.8(71)$ & $43.6(34)$ & $78.7(37)$ & \\
\hline$\%$ Mixed & $24.0(30)$ & $28.2(22)$ & $17.0(8)$ & \\
\hline \% Emphysema $(-950 \mathrm{HU})^{\|}$ & $44.0 \pm 13.2$ & $46.9 \pm 12.9$ & $39.2 \pm 12.2$ & 0.0012 \\
\hline \% Air trapping (-856 HU)" & $75.2 \pm 11.6$ & $77.7 \pm 10.4$ & $71.1 \pm 12.4$ & 0.0017 \\
\hline
\end{tabular}

Definition of abbreviations: $B M I=$ body mass index; $B O D E=$ body mass index, airflow obstruction, dyspnea and exercise capacity; $6 M W D=6$-minute-walk distance; $R V=$ residual volume; $T L C=$ total lung capacity; $F E V_{1}=$ forced expiratory volume in 1 second; $P B=$ post-bronchodilator; $S G R Q=S t$. George's Respiratory Questionnaire; $H U=$ Hounsfield unit.

${ }^{*}$ Continuous variables presented as mean \pm standard deviation; categorical variables as percent (number, $n$ ) of patients.

${ }^{+}$All RENEW patients bilaterally treated with coils and with evaluable inspiratory and expiratory scans at baseline and 12 months.

${ }^{\ddagger} p$-values comparing densitometry targeted and non-densitometry targeted groups are based on twosided t-test for continuous variables and Fisher's exact test for categorical variables.

${ }^{\S}$ Requires $\geq 15 \%$ difference in \% emphysema between upper and lower lobes $-950 \mathrm{HU}$, in both lungs. "Average value for two QCT targeted lobes. 
Table 2. Baseline Characteristics associated with Lobar RV Change at 12-months in Responder Analysis cohort ( $\mathrm{N}=78)$.

\begin{tabular}{|c|c|c|c|}
\hline PARAMETER & CORRELATION & P-VALUE & $\begin{array}{l}\text { Correlation } \\
\text { Coefficient, } r\end{array}$ \\
\hline \multicolumn{4}{|l|}{ Bivariate } \\
\hline $\begin{array}{l}\text { \% Emphysema, } \\
\text { Minimum of both treated lobes }\end{array}$ & - & 0.0063 & -0.3067 \\
\hline $\begin{array}{l}\text { Visual CT presence of airways } \\
\text { disease }\end{array}$ & + & 0.0117 & 0.2841 \\
\hline $\begin{array}{l}\% \text { Heterogeneity between ipsilateral } \\
\text { lobes }\end{array}$ & - & 0.0118 & -0.2837 \\
\hline BMI & + & 0.0464 & 0.2262 \\
\hline
\end{tabular}

Multivariate (Stepwise) $R^{2}=0.1773, P=0.0023$

\begin{tabular}{lcc}
\hline \% Emphysema, & - & 0.0244 \\
Minimum of both treated lobes & & \\
Visual CT Presence of Airways & + & 0.0313 \\
Disease & & \\
RV \% predicted & - & 0.0710 \\
\hline
\end{tabular}

Only statistically significant predictors are shown for univariate analysis $(P<0.05)$. Multivariate regression model with stepwise control using minimum Akaike Information Criterion (AICC) stopping rule in forward direction. $B M I=$ body mass index; $C T=$ computed tomography; $R V=$ residual volume. 
Table 3. Clinical Outcomes by Volume Reduction Criteria* in Responder Analysis cohort ( $N=78)$.

\begin{tabular}{|c|c|c|c|c|c|c|c|c|c|}
\hline & \multicolumn{4}{|c|}{$\begin{array}{l}\text { Patients with Volume Reduction Criteria } \\
(\mathrm{N}=50)\end{array}$} & \multicolumn{4}{|c|}{$\begin{array}{l}\text { Patients without Volume Reduction Criteria } \\
(\mathrm{N}=28)\end{array}$} & \multirow{2}{*}{$\begin{array}{l}\text { P- } \\
\text { Value }\end{array}$} \\
\hline & Mean & SE & Median & (IQR) & Mean & SE & Median & (IQR) & \\
\hline$R V, L$ & -0.57 & 0.13 & -0.44 & $(-1.19,-0.10)$ & -0.20 & 0.16 & -0.02 & $(-0.67,0.38)$ & 0.0793 \\
\hline VC, L & 0.31 & 0.06 & 0.27 & $(0.09,0.55)$ & 0.11 & 0.08 & 0.09 & $(-0.25,0.32)$ & 0.0470 \\
\hline FEV1, \% & 15.2 & 3.1 & 13.6 & $(1.4,21.9)$ & 0.6 & 3.5 & -0.9 & $(-13.3,10.1)$ & 0.0038 \\
\hline FEV1, L & 0.097 & 0.022 & 0.075 & $(0.010,0.145)$ & -0.005 & 0.024 & -0.005 & $(-0.103,0.067)$ & 0.0040 \\
\hline $\begin{array}{l}\text { Lobar Volume, } \\
\mathrm{mL}\end{array}$ & -467 & 64 & -402 & $(-670,-128)$ & -103 & 78 & -68 & $(-264,145)$ & 0.0007 \\
\hline 6MWD, m & 16 & 11 & 24 & $(-2,63)$ & -7 & 12 & -13 & $(-46,41)$ & 0.1935 \\
\hline SGRQ, pts & -12 & 2 & -13 & $(-19,-3)$ & -4 & 3 & -2 & $(-9,6)$ & 0.0100 \\
\hline mMRC, pts & -0.8 & 0.2 & -1.0 & $(-2.0,0.0)$ & -0.8 & 0.2 & -1.0 & $(-1.8,0.0)$ & 0.9040 \\
\hline
\end{tabular}

$6 M W D=6$-minute-walk distance; FEV1 = forced expiratory volume in 1 second; $I Q R=$ interquartile range; $R V=$ residual volume; $S Q R Q=S t$. George's Respiratory Questionnaire; $V C=$ vital capacity. $P$-Values = analysis of variance for continuous outcomes, 2-Tail Fisher's exact test for categorical outcomes. *Volume Reduction criteria: QVM+, \%Emphysema $\geq 20 \%$ and RV $\geq 200 \%$ predicted, no visual CT presence of airways disease. 
Table 4. Summary of Major Complications Through 12 Months ( $N=125)$

\begin{tabular}{|c|c|c|c|c|c|}
\hline \multirow[b]{2}{*}{ Major Complication Event } & \multicolumn{2}{|c|}{$\begin{array}{l}\text { Patients with Volume Reduction } \\
\text { Criteria }(\mathrm{N}=50)\end{array}$} & \multicolumn{2}{|c|}{$\begin{array}{l}\text { Group without All Volume } \\
\text { Reduction Criteria ( } N=75)\end{array}$} & \multirow[b]{2}{*}{ P-value* } \\
\hline & $\begin{array}{c}\text { Subject Counts } \\
n(\%)\end{array}$ & $\begin{array}{c}\text { Event Counts } \\
\mathbf{n}\end{array}$ & $\begin{array}{c}\text { Subject Counts } \\
\text { n (\%) }\end{array}$ & $\begin{array}{c}\text { Event Counts } \\
n\end{array}$ & \\
\hline Total Major Complication Events & $14(28.0 \%)$ & 17 & $19(25.3 \%)$ & 31 & 0.8365 \\
\hline Death & $0(0.0 \%)$ & 0 & $0(0.0 \%)$ & 0 & $\mathrm{~N} / \mathrm{A}$ \\
\hline Pneumothorax & $1(2.0 \%)$ & 1 & $0(0.0 \%)$ & 0 & 0.4000 \\
\hline Hemoptysis & $0(0.0 \%)$ & 0 & $1(1.3 \%)$ & 1 & 1.0000 \\
\hline COPD Exacerbation & $5(10.0 \%)$ & 5 & $8(10.7 \%)$ & 11 & 1.0000 \\
\hline $\begin{array}{l}\text { Lower Respiratory } \\
\text { Infection }\end{array}$ & $8(16.0 \%)$ & 10 & $12(16.0 \%)$ & 16 & 1.0000 \\
\hline Respiratory Failure & $1(2.0 \%)$ & 1 & $3(4.0 \%)$ & 3 & 0.6492 \\
\hline $\begin{array}{l}\text { Unanticipated } \\
\text { Bronchoscopy }\end{array}$ & $0(0.0 \%)$ & 0 & $0(0.0 \%)$ & 0 & $\mathrm{~N} / \mathrm{A}$ \\
\hline
\end{tabular}

"By Fisher's exact test. Subjects are counted at most once for each major complication event. 
125 RENEW Patients received bilateral coil treatment with completed 12-month follow-up visit* and analysable CT scans ("RENEW QCT Cohort")

47 Patients that were not treated in the lobes determine by QCT [QVM(-)]

78 Patients treated in the lobes determined by QCT [QVM(+)] ("Responder Analysis Cohort")

28 Patients with low hyperinflation (baseline RV $<200 \%$ pred),

or low emphysema (lobar \%emphysema $<20 \%$ in either of the treated lobes), or visual presence of airways disease

50 Patients treated in the lobes determined by QCT and meeting baseline criteria for volume reduction ("Volume Reduction Criteria")

${ }^{*}$ Any 1 of the PFTs was measured at 12 months. 


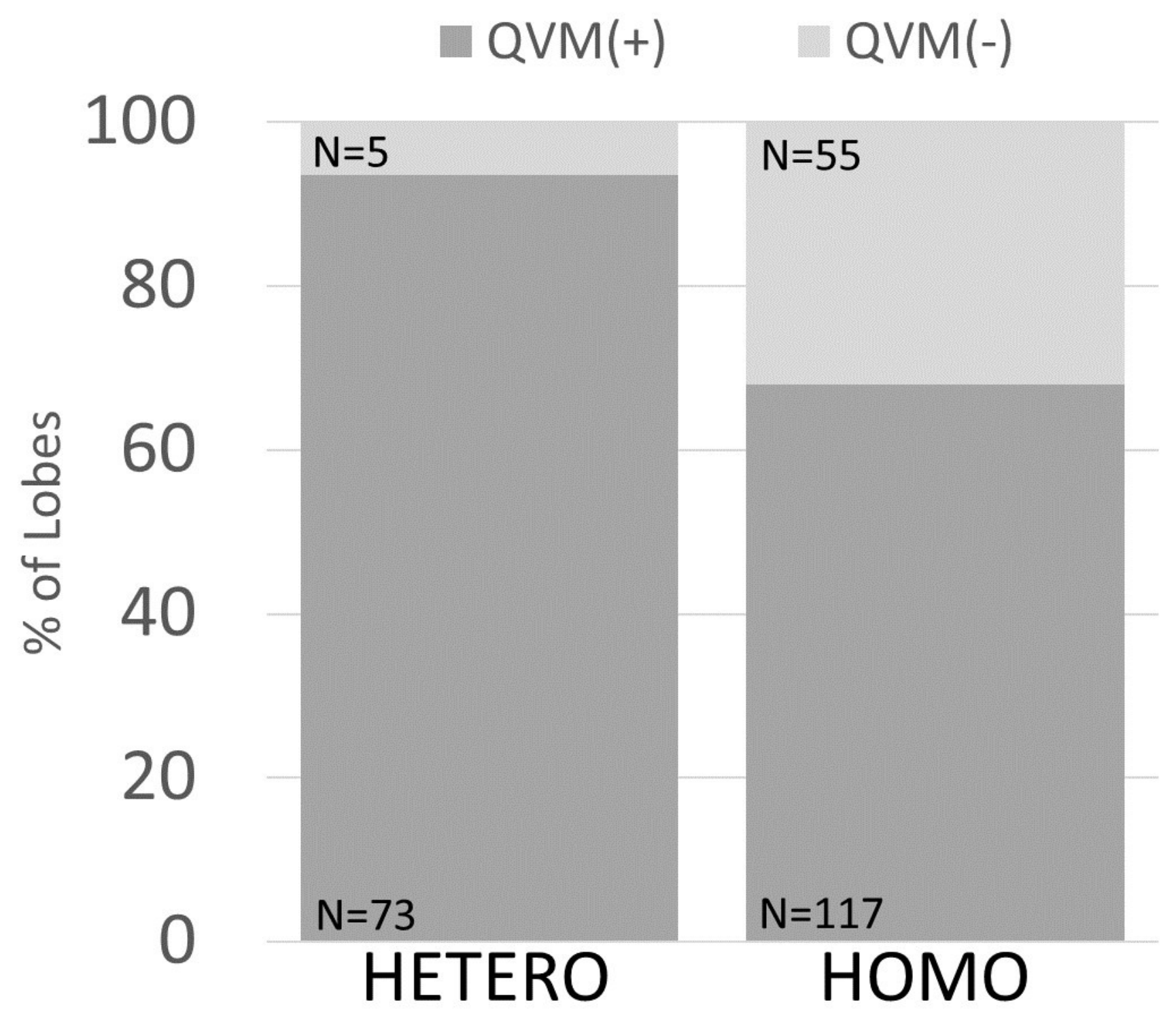




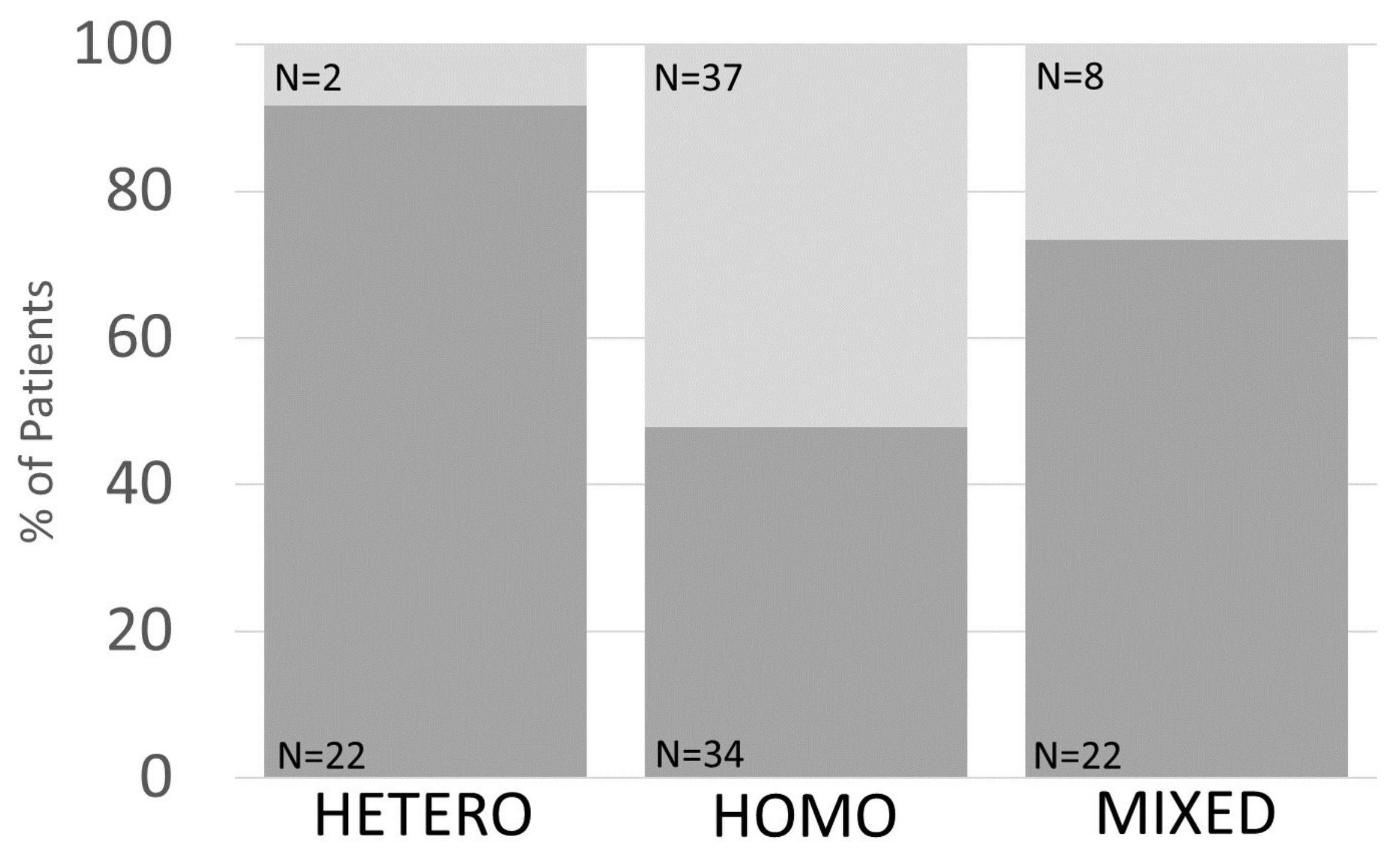


$=-10.859 x+128.95$ $R^{2}=0.0941$

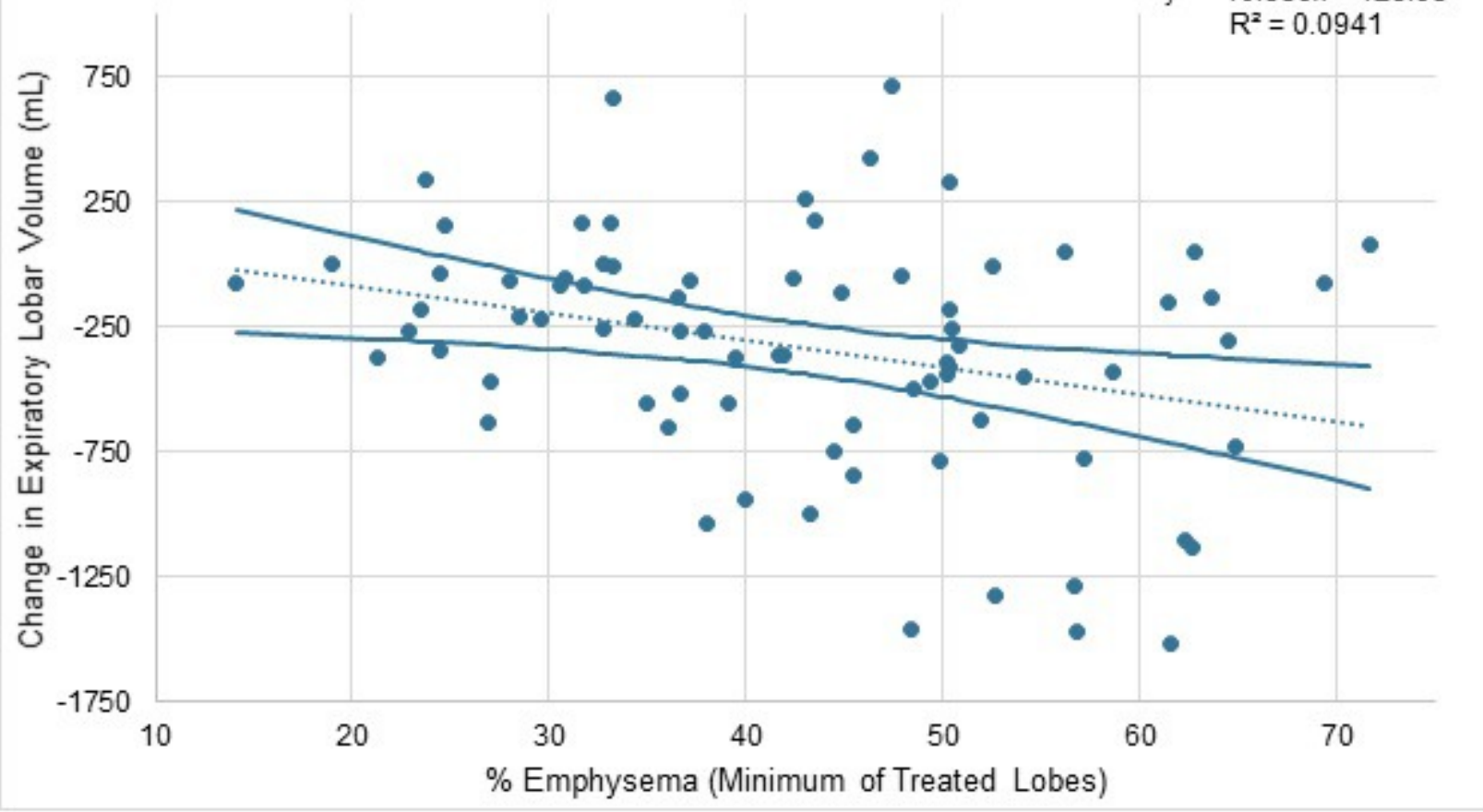




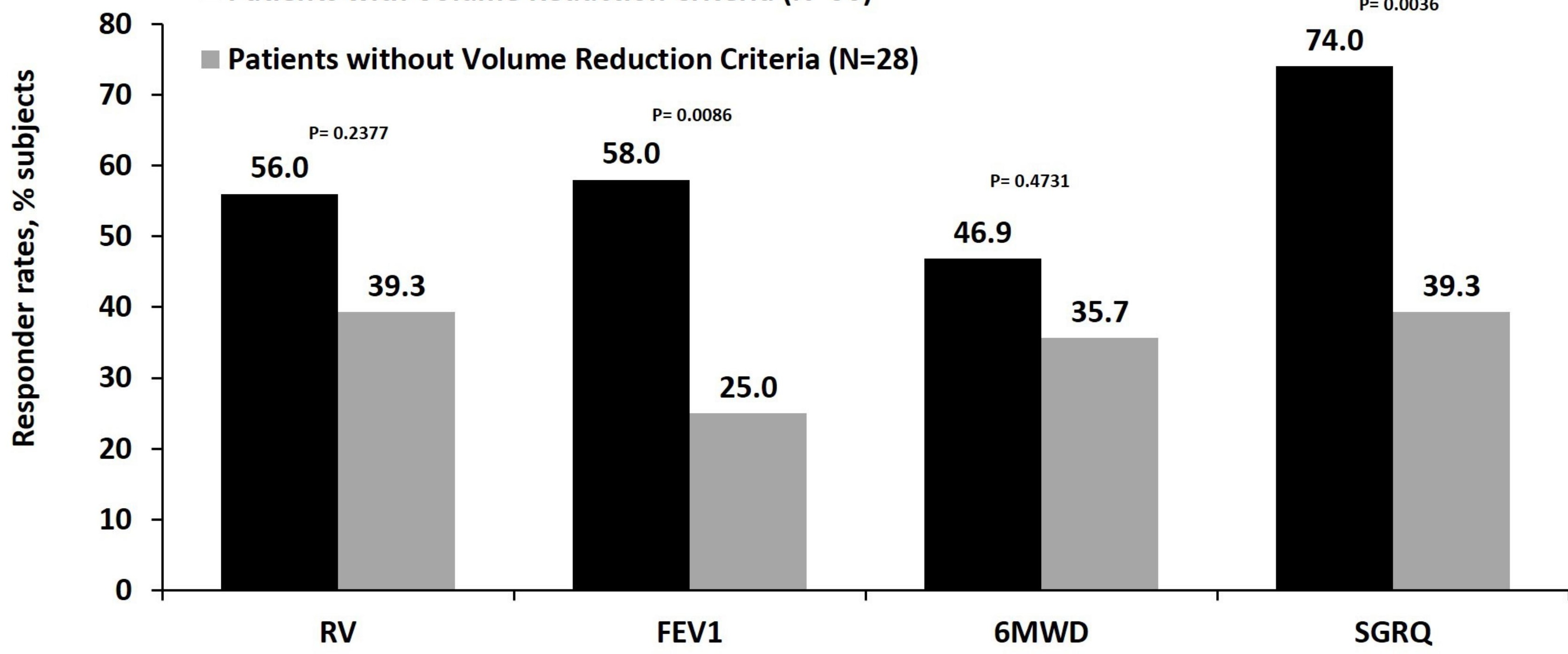

